\title{
Constraints on inorganic gaseous iodine in the tropical upper troposphere and stratosphere inferred from balloon-borne solar occultation observations
}

\author{
A. Butz ${ }^{1,{ }^{*}, \text { H. Bösch }}{ }^{3,}{ }^{*}$, C. Camy-Peyret ${ }^{4}$, M. P. Chipperfield ${ }^{5}$, M. Dorf ${ }^{2}$, S. Kreycy ${ }^{2}$, L. Kritten ${ }^{2}$, C. Prados-Román ${ }^{2}$, \\ J. Schwärzle ${ }^{2}$, and K. Pfeilsticker ${ }^{2}$ \\ ${ }^{1}$ SRON - Netherlands Institute for Space Research, Utrecht, The Netherlands \\ ${ }^{2}$ Institut für Umweltphysik, University of Heidelberg, Heidelberg, Germany \\ ${ }^{3}$ Department of Physics, University of Leicester, Leicester, UK \\ ${ }^{4}$ Laboratoire de Physique Moléculaire pour l'Atmosphère et l'Astrophysique (LPMAA), Université Pierre et Marie Curie, \\ Paris, France \\ ${ }^{5}$ Institute for Climate and Atmospheric Science, School of Earth and Environment, University of Leeds, Leeds, UK \\ * formerly at: Institut für Umweltphysik, University of Heidelberg, Heidelberg, Germany
}

Received: 14 May 2009 - Published in Atmos. Chem. Phys. Discuss.: 7 July 2009

Revised: 10 September 2009 - Accepted: 11 September 2009 - Published: 29 September 2009

\begin{abstract}
We report upper limits of IO and OIO in the tropical upper troposphere and stratosphere inferred from solar occultation spectra recorded by the LPMA/DOAS (Limb Profile Monitor of the Atmosphere/Differential Optical Absorption Spectroscopy) payload during two stratospheric balloon flights from a station in Northern Brazil $\left(5.1^{\circ} \mathrm{S}\right.$, $42.9^{\circ} \mathrm{W}$ ). In the tropical upper troposphere and lower stratosphere, upper limits for both, IO and OIO, are below $0.1 \mathrm{ppt}$. Photochemical modelling is used to estimate the compatible upper limits for the total gaseous inorganic iodine burden $\left(\mathrm{I}_{\mathrm{y}}\right)$ amounting to 0.09 to $0.16(+0.10 /-0.04) \mathrm{ppt}$ in the tropical lower stratosphere $(21.0 \mathrm{~km}$ to $16.5 \mathrm{~km})$ and 0.17 to $0.35(+0.20 /-0.08) \mathrm{ppt}$ in the tropical upper troposphere $(16.5 \mathrm{~km}$ to $13.5 \mathrm{~km})$. In the middle stratosphere, upper limits increase with altitude as sampling sensitivity decreases. Our findings imply that the amount of gaseous iodine transported into the stratosphere through the tropical tropopause layer is small. Thus, iodine-mediated ozone loss plays a minor role for contemporary stratospheric photochemistry but might become significant in the future if source gas emissions or injection efficiency into the upper atmosphere are enhanced. However, photochemical modelling uncertainties are large and iodine might be transported into the stratosphere in particulate form.
\end{abstract}

Correspondence to: A. Butz

(a.butz@ sron.nl)

\section{Introduction}

Inorganic iodine species have been suggested as efficient catalysts for ozone $\left(\mathrm{O}_{3}\right)$ destruction in the troposphere and in the stratosphere (e.g. Solomon et al., 1994; Davis et al., 1996). Photochemical processing of iodine-bearing source gases yields atomic iodine (I) which readily reacts with $\mathrm{O}_{3}$ forming iodine monoxide (IO) radicals. The latter further react with other halogen oxides ( $\mathrm{XO}$ with $\mathrm{X}=\mathrm{I}, \mathrm{Br}, \mathrm{Cl}$ ), hydroxyl radicals or nitrogen oxides. Eventually, atomic iodine is recovered and ozone is catalytically removed from the atmosphere. Thereby, iodine is - on a per atom basis - a few hundred times more efficient at destroying ozone than chlorine (Law et al. (2006) referred to as WMO-2006 in the following).

All source gases of reactive iodine $\left(\mathrm{IO}_{\mathrm{x}}=\mathrm{IO}+\mathrm{I}\right)$ are very short-lived (lifetime $<6$ months) iodinated compounds. Among the organic source gases, methyl iodide $\left(\mathrm{CH}_{3} \mathrm{I}\right)$ is the generally most abundant one due to its comparatively long atmospheric lifetime of $\sim 7$ days and due to sizable emissions from algae and oceanic surface waters (WMO-2006). Measurements in marine boundary layer air indicate that background $\mathrm{CH}_{3} \mathrm{I}$ concentrations range between $0.1 \mathrm{ppt}$ and $2 \mathrm{ppt}$ (Butler et al., 2007; Yokouchi et al., 2008) with higher values reported from North Atlantic coastal source regions (e.g. Peters et al., 2005). Following emission by certain types of algae, molecular iodine $\left(I_{2}\right)$ has been identified as an inorganic source of $\mathrm{IO}_{\mathrm{x}}$ in the coastal boundary layer (e.g. Finley and Saltzman, 2008). Reactive iodine itself has been

Published by Copernicus Publications on behalf of the European Geosciences Union. 
observed regularly in the form of IO radicals in the lower troposphere with concentrations of several ppt (e.g. Frieß et al., 2001; Peters et al., 2005; Zingler and Platt, 2005; SaizLopez et al., 2006, 2007b; Read et al., 2008). Only recently, space-borne observations confirmed enhanced levels of IO near coastal Antarctica (Saiz-Lopez et al., 2007a; Schönhardt et al., 2008). Removal of iodine-bearing compounds from the gas-phase can occur through uptake by aerosols and through nucleation of new particles initiated by polymerization of iodine oxides (e.g. Pechtl et al., 2006, 2007; Gilfedder et al., 2008).

Since iodine-containing source gases and their breakdown products released into the boundary layer are very short-lived, their importance for the upper troposphere and stratosphere strongly depends on the location and timing of sources with respect to atmospheric transport patterns that can potentially uplift air masses into the upper troposphere on short timescales (Yano et al., 2003). Recently, evidence has been accumulated that short-lived bromine species contribute significantly to the stratospheric bromine budget (e.g Dorf et al., 2006, 2008) suggesting a similar role of short-lived iodine sources. WMO-2006 estimate $0.02 \mathrm{ppt}$ to $0.18 \mathrm{ppt} \mathrm{CH}_{3} \mathrm{I}$ in the tropical upper troposphere and Davis et al. (1996) report $0.1 \mathrm{ppt}$ to $1 \mathrm{ppt} \mathrm{CH}_{3} \mathrm{I}$ in the tropical and subtropical free troposphere. Deep convective events could also transport iodine-containing particles into the dry upper troposphere where the particles can survive wash-out, climb into the stratosphere and eventually evaporate at higher altitudes. Murphy et al. (1998), Murphy and Thomson (2000), and Murphy et al. (2007) indeed found iodine in upper tropospheric and lower stratospheric particles. Most studies investigating the abundances of inorganic iodine species (IO and/or OIO) in the stratosphere conclude undetectably low amounts (Wennberg et al., 1997; Pundt et al., 1998; Bösch et al., 2003; Berthet et al., 2003). To date, the lowest estimate for the upper limit of the total gaseous inorganic iodine $\left(\mathrm{I}_{\mathrm{y}}\right)$ burden in the high- and mid-latitude lower stratosphere is $\sim 0.1 \mathrm{ppt}$ (Bösch et al., 2003). The only study claiming detectable amounts of $\mathrm{IO}$ in the high-latitude winter stratosphere is Wittrock et al. (2000) based on ground-based zenith-sky observations (see discussion in WMO-2006).

So far, little is known about the iodine budget in the tropical upper troposphere/lower stratosphere (UT/LS). The tropical UT/LS is the region in the Earth's atmosphere where tropospheric air masses are efficiently transported into the stratosphere and where the stratosphere is supplied with halogen-bearing compounds. Typically, air mass transport into the lower part of the tropical tropopause layer (TTL, $\sim 14 \mathrm{~km}$ to $\sim 18 \mathrm{~km}$ ) is very fast through convective events. Further upward transport into the stratosphere occurs on timescales of weeks to months through the large scale dynamics of the Brewer-Dobson circulation (Park et al., 2007; Schoeberl et al., 2008; Fueglistaler et al., 2009). Hence, the tropical UT/LS is dynamically linked to the lower troposphere allowing for rapid uplift of halogen source gases

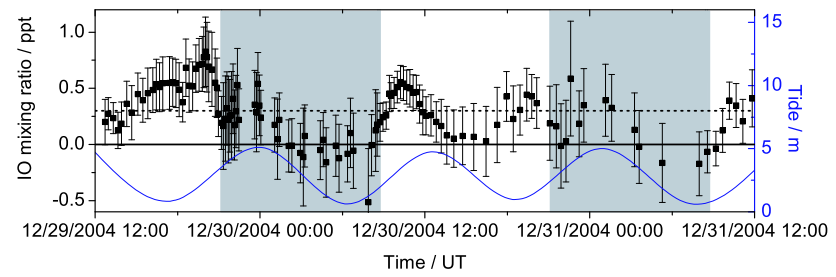

Fig. 1. Time series of IO measured along a $29 \mathrm{~km}$ absorption path in the marine boundary layer nearby Alcântara $2.4^{\circ} \mathrm{S}, 44.4^{\circ} \mathrm{W}$ ), Brazil. The left abscissa shows inferred IO volume mixing ratio (boxes with error bars). The right abscissa correlates the local tides (blue line). The detection limit of the experiment is estimated $0.3 \mathrm{ppt}$ (dotted black line). Nighttime is shaded grey.

or their breakdown products. Yet, transport timescales to the lower stratosphere allow for horizontal mixing of air masses and for photochemical processing of iodine source gases. Thus, observations of reactive iodine species in the tropical UT/LS should be well suited to constrain the budget of gaseous iodine transported into the stratosphere and available for further transport to high and mid-latitudes.

Our study reports on the attempt to measure IO and OIO abundances in the tropical UT/LS. The approach is based on balloon-borne solar absorption spectroscopy as presented by Bösch et al. (2003). The observations were conducted by the LPMA/DOAS (Limb Profile Monitor of the Atmosphere/Differential Optical Absorption Spectroscopy) stratospheric balloon payload. Launched from a site in Northern Brazil (Teresina, $5.1^{\circ} \mathrm{S}, 42.9^{\circ} \mathrm{W}$ ), LPMA/DOAS performed solar occultation measurements during sunset/sunrise in June 2005 and June 2008. Six months before the first balloon flight, we conducted ground-based measurements at the Brazilian coast (Alcântara, $2.4^{\circ} \mathrm{S}, 44.4^{\circ} \mathrm{W}$ ) approximately $350 \mathrm{~km}$ to the north-east of the balloon launch site. From spectra recorded in the visible spectral range by a long-path DOAS setup comparable to the one described in Peters et al. (2005), we infer IO abundances along a $29 \mathrm{~km}$ absorption path in the marine boundary layer between the mainland and an island in the bay of Sao Marcos. IO concentrations up to $(0.82 \pm 0.31)$ ppt (Fig. 1) suggest that our larger sampling area is a source region of iodinated compounds.

Here, we first analyze the collected balloon-borne spectra for absorption of IO and OIO in the visible spectral range (see Sect. 2 for the methods and Sect. 3 for the results). Then, we adopt a photochemical model (Sect. 4) that simulates the partitioning among gaseous inorganic iodine species in order to estimate $\mathrm{I}_{\mathrm{y}}$ in the tropical upper troposphere and stratosphere compatible with the inferred abundances of IO and OIO (Sect. 5). Finally we discuss (Sect. 6) and summarize our findings (Sect. 7). 


\section{IO and OIO retrieval from LPMA/DOAS observa- tions}

The LPMA/DOAS stratospheric balloon payload consists of two UV/visible grating (DOAS) (Ferlemann et al., 2000) and a Fourier Transform infrared spectrometer (LPMA) (CamyPeyret et al., 1995). The spectrometers simultaneously measure direct solar spectra during balloon ascent/descent and in solar occultation viewing geometry during sunset/sunrise. An automated heliostat collects direct sunlight and feeds it into the spectrometer optics such that the instruments sample virtually the same air masses along the lines-of-sight from the balloon to the Sun.

Here, we use retrievals from solar occultation measurements of the DOAS spectrometer sensitive to the visible spectral range. Spectrometer design is described in detail by Ferlemann et al. (2000) and with emphasis on IO and OIO retrievals by Bösch et al. (2003). Recently, the instrument has been optimized for IO retrievals by shifting the covered spectral range to shorter wavelengths $[400.2 \mathrm{~nm}, 653.0 \mathrm{~nm}]$ such that an additional vibrational excitation band $(5 \leftarrow 0)$ of the IO ground state transition to the first electronically excited state $\left(\mathrm{A}^{2} \Pi_{3 / 2} \leftarrow \mathrm{X}^{2} \Pi_{3 / 2}\right)$ centered around $419.5 \mathrm{~nm}$ can be used for IO retrievals. Further, for the most recent balloon flight in June 2008, light throughput has been increased by enlarging the light intake telescope by a factor 2 in acceptance area and replacing a degraded glass fibre bundle. The typical sampling rate for solar occultation measurements is $0.2 \mathrm{~Hz}$.

The recorded solar occultation spectra are analyzed for absorption of the target species by inferring absorber concentrations integrated along the lines-of-sight (Slant Column Densities - SCD) using the Differential Optical Absorption Spectroscopy (DOAS) method (Platt and Stutz, 2006). By ray-tracing the path of the incoming light from the Sun to the balloon-borne detector for each spectrum, we estimate absorber concentrations from the inferred SCDs under the assumption that the absorber volume mixing ratio is constant along individual lines-of-sight. This yields an approximate estimate of the absorber concentration at the respective tangent height since, for our solar occultation viewing geometry, the lightpath through the tangent layer dominates the entire lightpath. Thereby, the ray-tracing model assumes a spherical, refractive, horizontally homogeneous, non-scattering atmosphere where ambient pressure and temperature are provided by the meteorological support of the balloon flight.

The DOAS approach relies on least-squares fitting the logarithmic ratio $\ln I / I_{0}$ to a model function with the spectrum under investigation $I$ and a background spectrum $I_{0}$. Here, background spectra are recorded at solar zenith angles between $89^{\circ}$ and $90^{\circ}$ while the balloon floats at approximately constant altitude shortly before sunset or shortly after sunrise. Thereby, we implicitly assume that the background spectra contain only negligible absorption by the target species. The model function accounts for molecular ab- sorption along the light path according to Beer-Lambert's law, for broadband extinction by molecules and particles, and for instrumental effects. Molecular absorption is considered by fitting molecular absorption cross sections with the SCDs as retrieval parameters. Broadband extinction processes are fitted by a polynomial. In addition, the retrieval corrects for instrumental straylight by allowing for a closure polynomial that is subtracted from the raw spectra. The relative wavelength alignment of the background spectrum, the retrieval spectrum and the absorption cross sections is determined by various test runs. For the final retrieval, the relative wavelength alignment of the absorption cross sections and the background spectrum is fixed and only the retrieval spectrum is allowed to shift and stretch.

The spectral retrieval of IO follows the recommendations of Bösch et al. (2003) with minor modifications owing to the improved spectral coverage of the spectrometer. The spectral range for IO retrieval is extended to [416 nm, $465 \mathrm{~nm}$ ] (compared to [425 nm, $465 \mathrm{~nm}$ ] in Bösch et al. (2003)) covering six strong $(5 \leftarrow 0,4 \leftarrow 0,3 \leftarrow 0,2 \leftarrow 0,1 \leftarrow 0,0 \leftarrow 0)$ vibrational bands of the IO A ${ }^{2} \Pi_{3 / 2} \leftarrow X^{2} \Pi_{3 / 2}$ electronic transition. We use the IO absorption cross section measured by Hönninger (1999), scaled to Bloss et al. (2001), spectrally aligned to the $\mathrm{NO}_{2}$ absorption cross section of Harder et al. (1997), and convolved to our spectral resolution. Hönninger (1999) recorded the IO absorption cross section at a spectral resolution of $0.09 \mathrm{~nm}$ (full width at half maximum (FWHM)) and found a peak cross section of $2.6 \times 10^{-17} \mathrm{~cm}^{2}$ of the $4 \leftarrow 0$ vibrational band at $427.2 \mathrm{~nm}$. Recent studies at a comparable spectral resolution indicate that the IO absorption cross section at $427.2 \mathrm{~nm}$ is as large as $3.5 \times 10^{-17} \mathrm{~cm}^{2}$ (Gómez Martín et al., 2005; Spietz et al., 2005; Dillon et al., 2005). In order to sustain consistency with the study by Bösch et al. (2003), we prefer the IO absorption cross section measured by Hönninger (1999) over the more recent measurements which would produce somewhat lower SCDs and lower upper limits (factor $\sim 0.75$ ).

In the IO retrieval range, ozone $\left(\mathrm{O}_{3}\right)$ and nitrogen dioxide $\left(\mathrm{NO}_{2}\right)$ are major absorbers with optical densities up to 0.05 . In the view of expected IO optical density less than $10^{-3}$, it is evident that $\mathrm{O}_{3}$ and $\mathrm{NO}_{2}$ absorption features have to be carefully accounted for in order to avoid contamination of the IO retrieval with artefacts due to misrepresentation of $\mathrm{O}_{3}$ or $\mathrm{NO}_{2}$. Therefore, we simultaneously fit absorption cross sections of $\mathrm{O}_{3}$ and $\mathrm{NO}_{2}$ recorded by the flight instrument in our lab-owned absorption cell setup at temperatures $T=200 \mathrm{~K}$ and $T=244 \mathrm{~K}$ for $\mathrm{O}_{3}$ and $T=200 \mathrm{~K}$ and $T=238 \mathrm{~K}$ for $\mathrm{NO}_{2}$ (Dorf, 2005). Using absorption cross sections measured by the actual flight instrument circumvents errors due to convolution of literature reference cross sections by the instrument function. Further, $\mathrm{NO}_{2}$ absorption cross sections are corrected for the so-called solar $I_{0}$ effect (Aliwell et al., 2002). Absorption of the oxygen collisional pair $\mathrm{O}_{4}$ is considered through the absorption cross section of Hermans et al. (1999). Broadband extinction is accounted for 

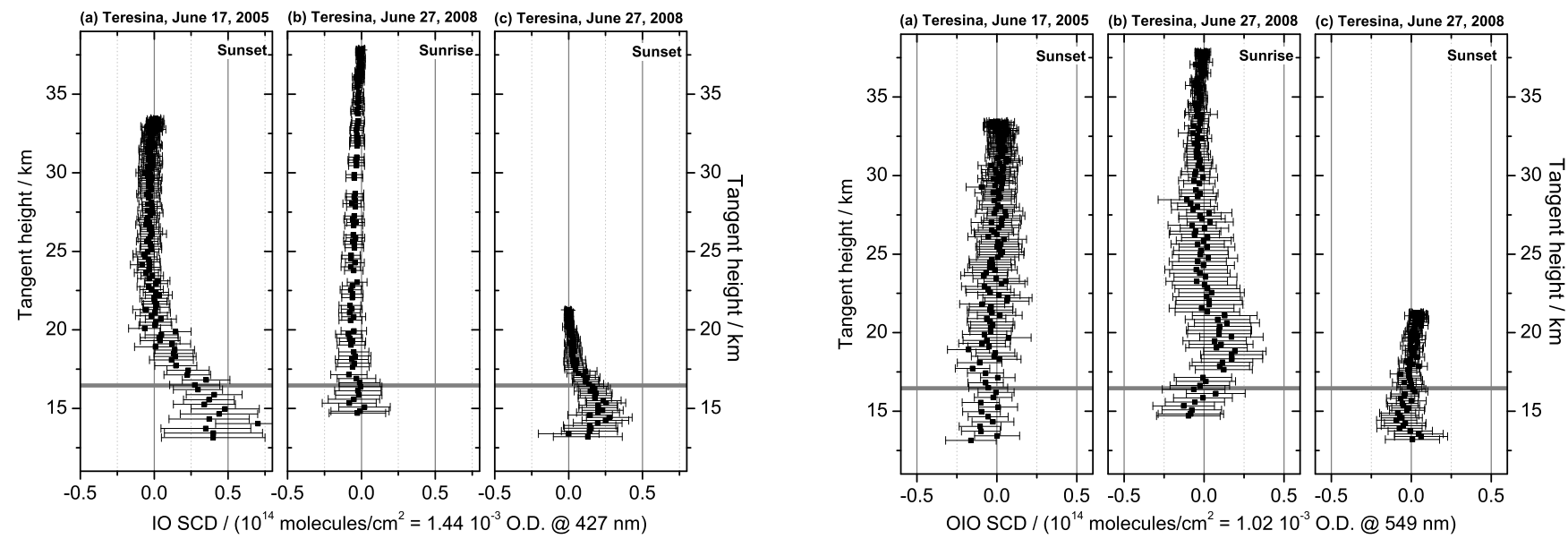

Fig. 2. IO (left panel) and OIO SCDs (right panel) as a function of tangent height for solar occultation measurements during sunset on 17 June 2005 (a), during sunrise on 27 June 2008 (b), and during sunset on 27 June 2008 (c). The error bars correspond to the statistical 2- $\sigma$ fitting errors of the DOAS retrieval. Optical density (O.D.) units are given for the peak of the IO absorption cross section at $427 \mathrm{~nm}$ (left panel) and for the peak of the OIO absorption cross section at $549 \mathrm{~nm}$ (right panel). The horizontal grey line tentatively marks the tropopause.

by a fourth-order polynomial, instrumental straylight through a first-order closure polynomial.

Bösch et al. (2003) pointed out that a correction of the Sun's center-to-limb darkening (CLD) is of major importance for IO retrievals from direct Sun spectra. The intensity of the solar disk shows a pronounced decrease from the center to the limb which goes along with a decrease of the observed optical density of the Fraunhofer lines. Our spectrograph measures solar disk average spectra of sunlight that passed through the Earth's atmosphere and hence, is sensitive to effects that affect the observed solar disk average. Such an effect occurs in solar occultation viewing geometry. Due to extinction in the Earth's atmosphere, light coming from the lower edge of the Sun is attenuated stronger than light coming from the upper edge. Thus, the upper part of the solar disk contributes relatively more to the observed solar disk average the deeper the lines-of-sight penetrate into the Earth's atmosphere. When ratioing solar occultation spectra by the background spectrum as in our DOAS retrieval, the CLD effect is detectable through a change of the optical density of the Fraunhofer lines. Neglecting the CLD effect can result in spurious detection of IO absorption. Thus, we adopt the correction method suggested by Bösch et al. (2003). The model function is supplemented by an additional term $a\left(I_{d}-I_{c}\right) / I_{d}$ where $I_{d}$ and $I_{c}$ are solar spectra averaged over the solar disk and taken from the disk center, respectively. $I_{d}$ and $I_{c}$ are generated from measurements of Brault and Neckel (1987) by convolution to our spectral resolution. The parameter $a$ is an additional fitting parameter.

Again following Bösch et al. (2003), OIO is retrieved in the $[530 \mathrm{~nm}, 570 \mathrm{~nm}]$ spectral range using the absorption cross section reported by Cox et al. (1999) who measured a value of $1.08 \times 10^{-17} \mathrm{~cm}^{2}$ at the peak of the vibra- tional band at $549 \mathrm{~nm}$ with $1.13 \mathrm{~nm}$ (FWHM) spectral resolution. This is in reasonable agreement with the more recent studies by Gómez Martín et al. (2005), Spietz et al. (2005), Joseph et al. (2005), and Tucceri et al. (2006). Ingham et al. (2000) inferred a significantly higher cross section up to $3.5 \times 10^{-17} \mathrm{~cm}^{2}$. The scaling used here comforms with the study of Bösch et al. (2003) and is at the lower limit of the reported range.

Interfering absorption due to $\mathrm{O}_{3}, \mathrm{NO}_{2}$, and $\mathrm{O}_{4}$ is treated as for the retrieval of IO. Additionally, $\mathrm{H}_{2} \mathrm{O}$ absorption is considered through a convolved absorption cross section generated from HITRAN (Rothman et al., 2005) line parameters for $T=213 \mathrm{~K}$ and $p=80 \mathrm{mbar}$. Broadband extinction and straylight correction are represented by a fourth and a firstorder polynomial, respectively. The CLD effect is found negligible for the chosen OIO retrieval range.

\section{Upper limits of IO and OIO}

The LPMA/DOAS gondola was launched from the tropical site Teresina $\left(5.1^{\circ} \mathrm{S}, 42.9^{\circ} \mathrm{W}\right)$ in Northern Brazil on 17 June 2005, and on 27 June 2008. In 2005, the payload conducted sunset solar occultation measurements from about $33 \mathrm{~km}$ balloon float altitude between 20:47 UT and 21:08 UT covering tangent heights (lowest altitude layer crossed by the line-of-sight) between $33 \mathrm{~km}$ and $13 \mathrm{~km}$. In 2008, the payload was launched during night. Sunrise solar occultation measurements from $38 \mathrm{~km}$ balloon float altitude were conducted continuously between 08:45 UT and 09:08 UT from tangent heights around $15 \mathrm{~km}$ up to $38 \mathrm{~km}$. During the day the balloon slowly descended to $21.5 \mathrm{~km}$ altitude in order to improve sampling sensitivity in the UT/LS. Sunset 
Table 1. IO and OIO upper limits (in ppt) ${ }^{\mathrm{a}}$ at several tangent heights (in km) inferred from LPMA/DOAS solar occultation observations conducted at Teresina $\left(5.1^{\circ} \mathrm{S}, 42.9^{\circ} \mathrm{W}\right)$, Brazil.

\begin{tabular}{cccccccccccc}
\hline Date & Geophysical & \multicolumn{4}{c}{ IO upper limit/ppt } & \multicolumn{4}{c}{ OIO upper limit/ppt } \\
& condition & $30 \mathrm{~km}$ & $24 \mathrm{~km}$ & $20 \mathrm{~km}$ & $16.5 \mathrm{~km}$ & $13.5 \mathrm{~km}$ & $30 \mathrm{~km}$ & $24 \mathrm{~km}$ & $20 \mathrm{~km}$ & $16.5 \mathrm{~km}$ & $13.5 \mathrm{~km}$ \\
\hline 17 June 2005 & tropics, sunset & 0.57 & 0.19 & 0.12 & 0.19 & 0.14 & 0.61 & 0.30 & 0.14 & 0.07 & 0.05 \\
27 June 2008 & tropics, sunrise & 0.31 & 0.14 & 0.09 & 0.08 & - & 0.52 & 0.40 & 0.21 & 0.10 & - \\
27 June 2008 & tropics, sunset & - & - & 0.04 & 0.09 & 0.07 & - & - & 0.06 & 0.05 & 0.06 \\
\hline
\end{tabular}

a Absorber volume mixing ratios are estimated from slant column densities under the assumption that the absorber volume mixing ratio is constant along individual lines-of-sight.

spectra were collected from 20:47 UT to 21:06 UT for tangent heights between $21.5 \mathrm{~km}$ and $13.2 \mathrm{~km}$. For both flights the tropopause was located around $16.5 \mathrm{~km}$.

For the three solar occultation events, Fig. 2 shows IO and OIO SCDs retrieved according to the DOAS method described in Sect. 2. The attributed error bars are the 2- $\sigma$ statistical retrieval errors calculated by the least-squares fitting routine. In DOAS applications, the 2- $\sigma$ retrieval error is commonly considered as the detection limit (Stutz and Platt, 1996; Bösch et al., 2003). Within their 2- $\sigma$ retrieval errors, the inferred IO and OIO SCDs are compatible or almost compatible with zero. In particular, this is true for all OIO SCDs, and the IO SCDs above $18 \mathrm{~km}$ tangent height. For the sunset data below $18 \mathrm{~km}$ tangent height, IO SCDs exceed the $2-\sigma$ error limit slightly but systematically. In the following, we discuss upper limits for both species where upper limits refer to the retrieved SCDs whenever they exceed the 2- $\sigma$ retrieval error and to the 2- $\sigma$ retrieval error otherwise.

Following this approach, Table 1 lists IO and OIO upper limits in mixing ratio units for selected tangent heights. In the UT/LS up to $20 \mathrm{~km}$ tangent height, upper limits for both, IO and OIO, are smaller than 0.1 ppt. Higher up, upper limits increase due to decreased sampling sensitivity for both species. These findings are consistent with IO and OIO upper limits found by Bösch et al. (2003) for the lower stratosphere at high and mid-latitudes. Table 1 essentially extends previous records by tropical observations.

For the sunset measurements in 2005 and 2008, IO SCDs exceed the statistical detection limit in the UT/LS. Whether this finding implies unambiguous detection of IO requires further discussion. Figure 3 compares the residual optical density of the DOAS retrievals with the optical density of the retrieved IO absorption at several tangent heights in the UT/LS. For illustration, simulated IO optical density is also shown assuming $0.5 \mathrm{ppt}$ (2005) and $0.25 \mathrm{ppt}$ (2008) IO along the lines-of-sight. Arguably, the retrieved IO optical density cannot be identified as true absorption when inspecting Fig. 3 by eye while the simulated IO absorption features are clearly identifiable. The residual optical density is dominated by a systematic pattern. Such systematic features can bias the retrieval of IO and cause spurious detection as, for example, shown by Bösch et al. (2003) when neglecting the CLD effect.
Although performing various sensitivity runs and test retrievals, we failed in removing the systematic features from the retrieval residuals. Inaccurate removal of $\mathrm{O}_{3}$ and $\mathrm{NO}_{2}$ absorption features is an obvious candidate that could produce the observed pattern. Unaccounted temperature or pressure dependence of the $\mathrm{O}_{3}$ and $\mathrm{NO}_{2}$ absorption cross sections could contribute. Further, any change of the instrument characteristics between the time when $\mathrm{O}_{3}$ and $\mathrm{NO}_{2}$ absorption cross sections were recorded and the actual atmospheric measurement can cause systematic residuals. Monitoring of the instrumental line shape by monochromatic emission lamps $(\mathrm{Hg}, \mathrm{Cd})$ reveals only negligible changes of the shape of the instrument function. By the time of the balloon flight in 2005 , however, we detect a shift of the wavelength-detectorpixel mapping by roughly one detector pixel. This shift is largely compensated by the spectral alignment parameters in the retrieval model function but interpolation errors may occur.

Bösch et al. (2003) speculated on deficiencies of the CLD correction term which is generated from convolving high resolution measurements of the solar disk average and solar disk center intensity. Convolution is carried out by an instrument function derived from emission lamp $(\mathrm{Hg}, \mathrm{Cd})$ spectra, but the spectral dependence of the instrument function is neglected. Further, the correction term itself is an empirical approach which might not be able to catch the entire CLD signal in our spectra, in particular since a CLD signal can be generated by any extinction process that modifies the composite solar disk average observed by the DOAS spectrograph. Lately, there has been evidence that particles are frequently present in the tropical upper troposphere (Lawson et al., 2008; Jensen et al., 2008). Extinction by particulate layers could cause a complex pattern of the observed CLD effect on our spectra and bias the IO retrieval if the applied CLD correction fails to fully account for it.

It is worth noting that the inferred IO SCDs systematically exceed the $2-\sigma$ error limit only for spectra where a part of the collected light traversed the troposphere. The effective field-of-view of the DOAS spectrometer is given by the size of the solar disk $\left(0.53^{\circ}\right)$. Neglecting refraction, a rough calculation shows that at a tropopause tangent height of $16.5 \mathrm{~km}$ the apparent diameter of the solar disk at the tangent point is approximately $4.3 \mathrm{~km}$ or $2.3 \mathrm{~km}$ for an observer 

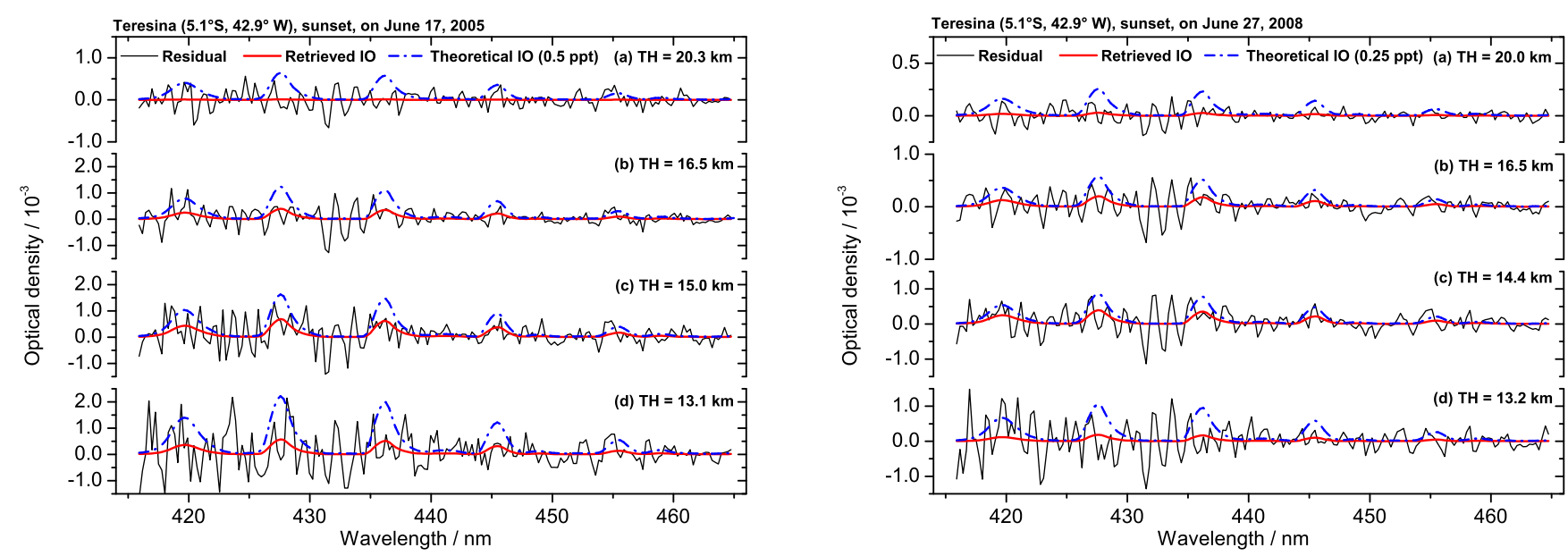

Fig. 3. Residual optical density (black thin solid), retrieved IO optical density (red bold solid), and theoretical IO optical density (blue dash-dotted) in the IO retrieval window for sunset on 17 June 2005, (left panel) and sunset, on 27 June 2008, (right panel) at the indicated tangent heights $(\mathrm{TH})$ for subpanels a to $\mathrm{d}$. The theoretical IO optical density is calculated assuming $0.5 \mathrm{ppt}$ (left panel) and $0.25 \mathrm{ppt}$ (right panel) IO along the lines-of-sight. The tropopause is at roughly $16.5 \mathrm{~km}$.

at $33 \mathrm{~km}$ or $21.5 \mathrm{~km}$, respectively. Hence, tropospheric air masses contribute to the observed spectra for tangent heights below $18.5 \mathrm{~km}$ and $17.5 \mathrm{~km}$ for the sunset records from 2005 and 2008, respectively. Unaccounted tropospheric absorbers such as water vapor could contribute to the observed residuals. Including a $\mathrm{H}_{2} \mathrm{O}$ absorption cross section generated from HITRAN (Rothman et al., 2005) in the DOAS model function, though, does not improve the fit.

Since the statistical detection limit does not consider the effect of systematic residual features, we conclude that neither IO nor OIO is unambiguously detectable from our tropical observations although retrieved IO SCDs exceed the 2- $\sigma$ error occasionally. However, our approach to estimate IO upper limits accounts for the possibility that IO abundances in the UT/LS are as high as suggested by the DOAS retrievals.

\section{Modelling inorganic iodine chemistry}

We are interested in the total gaseous inorganic iodine $\left(\mathrm{I}_{\mathrm{y}}\right)$ burden which is compatible with our estimates for IO and OIO. Thus, we adopt an updated version of the photochemical model of Bösch et al. (2003) that calculates the partitioning among inorganic iodine species in the tropical middle atmosphere.

The employed photochemical model is a 1-dimensional model that simulates the temporal evolution of chemical species given a set of gas-phase, heterogeneous and photolytic reactions. Photochemical reactions of all relevant oxygen, nitrogen, hydrogen, chlorine, and bromine species are considered as recommended by the JPL-2006 compendium on Chemical Kinetics and Photochemical Data for
Use in Atmospheric Studies (Sander et al., 2006). Photochemical reactions among the considered inorganic iodine species I, IO, OIO, HOI, HI, $\mathrm{IONO}_{2}$ are implemented according to Table 2 in Bösch et al. (2003) unless stated otherwise. Photolysis rates are calculated by a module adapted from the SLIMCAT 3-dimensional chemical transport model (Chipperfield, 1999, 2006). For the bulk of considered species, the 1-dimensional model is initialized by SLIMCAT output (run-id 336) for 00:05 UT on 17 June 2005, interpolated to the launch site of the balloon. For our purposes, we assume that this initialization is also valid for the flight on 27 June 2008. $\mathrm{O}_{3}$ and $\mathrm{NO}_{2}$ abundances are constrained by measurements of the DOAS instrument (Butz et al., 2007; Dorf et al., 2008). Iodine species are initialized assuming 0.2 ppt $\mathrm{I}_{\mathrm{y}}$ with a first guess partitioning. Test runs with $0.1 \mathrm{ppt}, 0.4 \mathrm{ppt}$, and $1.0 \mathrm{ppt} \mathrm{I}_{\mathrm{y}}$ show that for the considered range of iodine abundances the $\mathrm{I}_{\mathrm{y}}$ partitioning has a linear dependence on $\mathrm{I}_{\mathrm{y}}$. The 1-dimensional model is run on 19 potential temperature levels over 10 days to allow for spin up of the iodine partitioning. All model data shown here are taken from the 10th day of the respective model runs. Although the photochemical model has been designed to model photochemistry in the stratosphere, we consider it applicable to the tropical upper troposphere (above $\sim 13 \mathrm{~km}$ ) since all gaseous and surface reactions relevant to our study are incorporated. However, reactions in the aqueous phase important for the lower troposphere (e.g. Pechtl et al., 2006, 2007) are not included.

We define the total gaseous inorganic iodine burden $\mathrm{I}_{\mathrm{y}}=\mathrm{I}+\mathrm{IO}+\mathrm{OIO}+\mathrm{HOI}+\mathrm{HI}+\mathrm{IONO}_{2}$, where the sum refers to volume mixing ratio or number concentration. Our main interest is to model the partitioning $\mathrm{IO} / \mathrm{I}_{\mathrm{y}}$ and $\mathrm{OIO} / \mathrm{I}_{\mathrm{y}}$ in order 
to infer upper limits for $\mathrm{I}_{\mathrm{y}}$ given measured upper limits of IO and OIO. The major production mechanism of IO is the reaction of atomic iodine $\mathrm{I}$ with ozone $\mathrm{O}_{3}$,

$\mathrm{I}+\mathrm{O}_{3} \rightarrow \mathrm{IO}+\mathrm{O}_{2}$.

Removal of IO occurs via photolysis and reaction with $\mathrm{NO}, \mathrm{NO}_{2}$, and $\mathrm{HO}_{2}$,

$\mathrm{IO}+h v \rightarrow \mathrm{I}+\mathrm{O}$

$\mathrm{IO}+\mathrm{NO} \rightarrow \mathrm{I}+\mathrm{NO}_{2}$

$\mathrm{IO}+\mathrm{NO}_{2}+\mathrm{M} \rightarrow \mathrm{IONO}_{2}+\mathrm{M}$

$\mathrm{IO}+\mathrm{HO}_{2} \rightarrow \mathrm{HOI}+\mathrm{O}_{2}$

Reactive iodine, i.e. I and IO, may be recovered from the reservoirs $\mathrm{HOI}$ and $\mathrm{IONO}_{2}$ through photolysis.

$\mathrm{HOI}+h v \rightarrow \mathrm{I}+\mathrm{OH}$

$\mathrm{IONO}_{2}+h v \rightarrow \mathrm{IO}+\mathrm{NO}_{2}$.

The kinetics for the photolytic Reactions (R2), and (R6), as well as for Reaction (R4) are updated from Bösch et al. (2003) through the JPL-2006 recommendation. $\mathrm{IONO}_{2}$ photolysis (Reaction R7) has been subject of a recent study by Joseph et al. (2007) implying that $\mathrm{IONO}_{2}$ photolysis can be an order of magnitude slower than currently recommended by the study of Mössinger et al. (2002) merged into JPL2006. Further, Kaltsoyannis and Plane (2008) suggest that $\mathrm{IONO}_{2}$ could rapidly react with I implying a reduction of the $\mathrm{IONO}_{2}$ lifetime.

Interhalogen reactions play a key role in the production of OIO,

$$
\begin{aligned}
\mathrm{IO}+\mathrm{ClO} & \rightarrow \mathrm{OIO}+\mathrm{Cl} \\
& \rightarrow \text { products }
\end{aligned}
$$

$$
\begin{aligned}
\mathrm{IO}+\mathrm{BrO} & \rightarrow \mathrm{OIO}+\mathrm{Br} \\
& \rightarrow \text { products }
\end{aligned}
$$

$$
\begin{aligned}
\mathrm{IO}+\mathrm{IO} & \rightarrow \mathrm{OIO}+\mathrm{I} \\
& \rightarrow \text { products },
\end{aligned}
$$

where the OIO product yield from Reaction (R8) is small, but ranges between 0.65 and 1 for Reaction (R10). Reaction (R12) has recently been investigated by Joseph et al. (2005) and Gómez Martín et al. (2007) who estimate the branching ratio for OIO production to $0.31 \pm 0.10$ and $0.45 \pm 0.10$, respectively, which is in good agreement with the range adopted by Bösch et al. (2003). Other products of the IO self reaction are $\mathrm{I}_{2} \mathrm{O}_{2}$ and with a small yield $2 \mathrm{I}+\mathrm{O}_{2}$ and $\mathrm{I}_{2}+\mathrm{O}_{2}$. Thermal stability of $\mathrm{I}_{2} \mathrm{O}_{2}$ is subject of current debate (e.g. Kaltsoyannis and Plane, 2008). Sink processes for $\mathrm{OIO}$ are reactions with $\mathrm{NO}, \mathrm{OH}$,

$\mathrm{OIO}+\mathrm{NO} \rightarrow \mathrm{IO}+\mathrm{NO}_{2}$

$\mathrm{OIO}+\mathrm{OH} \rightarrow \mathrm{HOI}+\mathrm{O}_{2}$

and possibly photolysis,

$$
\begin{aligned}
\mathrm{OIO}+h v & \rightarrow \mathrm{IO}+\mathrm{O} \\
& \rightarrow \mathrm{I}+\mathrm{O}_{2} .
\end{aligned}
$$

Joseph et al. (2005) and Tucceri et al. (2006) conclude that absorption of radiation by OIO most likely does not result in OIO bond dissociation but rather production of excited OIO molecules and subsequent collisional quenching without dissociation of OIO. Both studies report upper limits for the OIO photolysis yield which are in good agreement with an upper limit fractional yield of 0.007 for Reaction (R16) and an upper limit fractional yield of 0.15 for Reaction (R17) found by Ingham et al. (2000). If OIO photolysis occurs at these upper limits (or possibly faster; Gómez Martín et al., 2008), OIO cannot contribute significantly to the $I_{y}$ partitioning in the tropical upper troposphere and stratosphere. Hence, we limit further discussion of the $\mathrm{I}_{\mathrm{y}}$ partitioning to the photochemical scenario where OIO photolysis does not occur at all. However, we consider efficient OIO photolysis for the error budget of modelled IO (see below).

Figure 4 shows the modelled partitioning among the considered iodine species under tropical conditions. The left panel of Fig. 4 corresponds to model runs for the case study in June 2005 where we found low $\mathrm{NO}_{2}$ abundances in the UT/LS. The right panel of Fig. 4 shows the $\mathrm{I}_{\mathrm{y}}$ partitioning modelled for our sunrise observations in June 2008 where $\mathrm{NO}_{2}$ concentrations in the UT/LS were enhanced. In general, processing of I to IO through Reaction (R1) is slow in the tropical UT/LS since $\mathrm{O}_{3}$ abundances are low. Depending on the availability of $\mathrm{O}_{3}$, I and IO compete for being the most abundant iodine species during the day when IO photolysis through Reaction (R2) is fast. During twilight, when our solar occultation measurements $\left(\mathrm{SZA} \sim 90^{\circ}\right.$ ) are conducted, IO abundances peak, since IO loss through photolysis decreases. Depending on the availability of $\mathrm{NO}_{2}$ and $\mathrm{HO}_{2}$, $\mathrm{IONO}_{2}$ and $\mathrm{HOI}$ are competing reservoirs formed through Reactions (R4) and (R5). For the flight in June 2005, HOI is the most important reservoir in the UT/LS while for the flight in June 2008, $\mathrm{IONO}_{2}$ is formed efficiently during twilight. Higher up in the atmosphere, concentrations of $\mathrm{O}_{3}$ and $\mathrm{NO}_{2}$ increase. IO becomes the most abundant daytime species at the expense of $\mathrm{I}$, and $\mathrm{IONO}_{2}$ becomes the most important nighttime reservoir and a daytime buffer for removal of IO into HOI. For OIO, production via the interhalogen Reactions (R8), (R10), and (R12), is slow in the tropical UT/LS due to low halogen abundances. At higher altitudes in the stratosphere, BrO abundances increase (Dorf et al., 2008) 

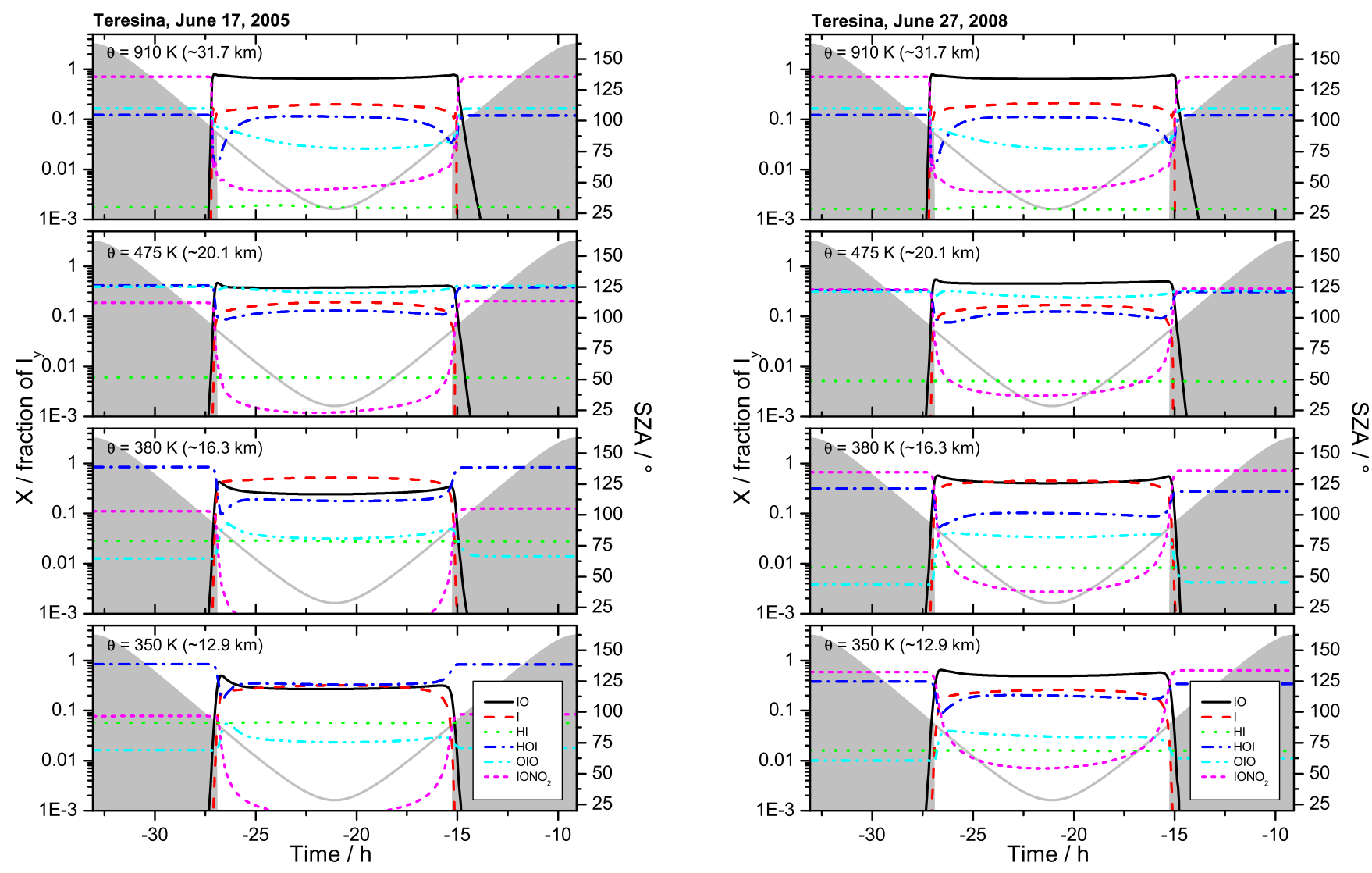

Fig. 4. $\mathrm{I}_{\mathrm{y}}$ partitioning among the indicated iodine species modelled for the flight in June 2005 (sunset) with low $\mathrm{NO}_{2}$ concentrations in the UT/LS (left panel) and for the flight in June 2008 (sunrise) with enhanced $\mathrm{NO}_{2}$ abundances in the UT/LS (right panel). All model runs assume that OIO photolysis does not occur. Several potential temperature $(\theta)$ levels ranging from the upper troposphere (lower subpanels) up to the mid-stratosphere (upper subpanels) are shown. The colour-coded lines depict the relative contribution of the respective species to total gaseous inorganic iodine $\mathrm{I}_{\mathrm{y}}$ through the left ordinate on a logarithmic scale. Illumination conditions are indicated by the solar zenith angle (grey line and shading) via the right ordinate. LPMA/DOAS observations are conducted at twilight $\left(\mathrm{SZA} \sim 90^{\circ}\right)$ during sunset and/or sunrise.

and OIO produced via Reaction (R10) becomes the second most abundant daytime $\mathrm{I}_{\mathrm{y}}$ component around $\sim 20 \mathrm{~km}$. At night, $\mathrm{OIO}$ is a reservoir which loses importance as $\mathrm{IONO}_{2}$ gains importance with altitude.

The employed photochemical scheme suffers from uncertainties of the adopted reaction kinetics. Therefore, we derive a photochemical modelling error. The uncertainties of the bi- and termolecular reactions among Reaction (R1) through Reaction (R15) are taken from Table 2 of Bösch et al. (2003) (or from the JPL-2006 recommendation if applicable). The uncertainty of the photolysis rate of $\mathrm{HOI}$ is assumed $50 \%$ while photolysis of IO is assumed uncertain by $30 \%$ as suggested by Bösch et al. (2003) from combining uncertainties of absorption cross sections and actinic fluxes. For photolysis of $\mathrm{IONO}_{2}$, we adopt $50 \%$ uncertainty for being faster than the JPL-2006 recommendation and the rate suggested by Joseph et al. (2007) for being slower. Further, we consider for the IO modelling error whether OIO photolysis does not occur or does occur according to the upper limits given by Ingham et al. (2000). Given these uncertainty estimates, Reaction (R1) through Reaction (R15) are individually tuned to their respective error limits with the goal to maximize/minimize the abundance of IO and OIO in the atmosphere. The error sensitivity of modelled IO and OIO to the respective reaction is given by the difference to the model base run. The overall photochemical modelling error is then calculated via Gaussian error propagation among the individual error sensitivities.

Under twilight conditions, the photochemical modelling error for IO is dominated by the uncertainty of OIO and $\mathrm{IONO}_{2}$ photolysis and by the uncertainty of IO production through $\mathrm{I}$ and $\mathrm{O}_{3}$ (Reaction R1). If the model allows for OIO photolysis, modelled IO is enhanced since IO is readily recovered from OIO. If $\mathrm{IONO}_{2}$ photolysis is slow, modelled IO is significantly reduced because $\mathrm{IO}$ tends to remain bound by its reservoir. In the UT/LS, uncertainty of HOI formation and 

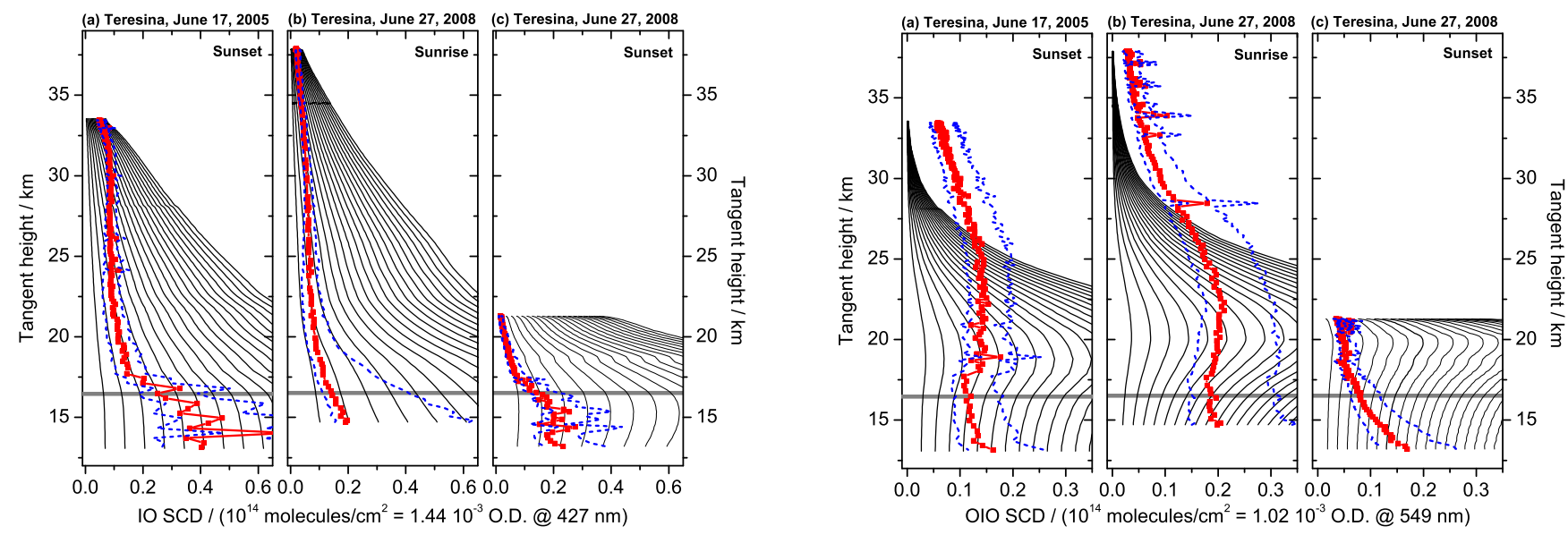

Fig. 5. Measured (red boxes) upper limits of IO (left panel) and OIO (right panel) and corresponding modelled (black lines) SCDs as a function of tangent height for sunset on 17 June 2005 (a), for sunrise on 27 June 2008 (b), and for sunset on 27 June 2008 (c). Modelled IO and OIO SCDs are shown for integer multiples of $0.1 \mathrm{ppt}$ total gaseous inorganic iodine $\mathrm{I}_{\mathrm{y}}$, i.e. the lowest black line corresponds to modelled IO or OIO SCDs if $\mathrm{I}_{\mathrm{y}}$ is $0.1 \mathrm{ppt}$, the second to lowest black line corresponds to modelled IO or OIO SCDs if $\mathrm{I}_{\mathrm{y}}$ is $0.2 \mathrm{ppt}$ and so forth. The intersection of measured IO and OIO upper limits with modelled SCDs yields the estimate of the respective $\mathrm{I}_{\mathrm{y}}$ upper limit. The photochemical modelling uncertainty is shown as error of the measured SCD upper limits (blue dotted lines). Model runs are performed under the assumption that OIO photolysis does not occur. The horizontal grey line tentatively marks the tropopause.

HOI photolysis through Reactions (R5) and (R6) also map into significant errors for modelled IO in particular if $\mathrm{NO}_{2}$ abundances are low and $\mathrm{HOI}$ is the dominating reservoir. The photochemical modelling error for OIO is governed by the uncertainty of reaction of $\mathrm{IO}$ with $\mathrm{BrO}$ (Reaction R10), and to a lesser extent by the uncertainty of OIO loss through reaction with NO (Reaction R14). Further, modelled OIO is reduced if the model assumes that $\mathrm{IONO}_{2}$ photolysis is slow implying that less IO is available to form OIO.

\section{Upper limits of total gaseous inorganic iodine}

Given measured upper limits of IO and OIO and the photochemical model described in Sect. 4, we compare SCDs modelled for different loadings of $\mathrm{I}_{\mathrm{y}}$ to the respective measured upper limits. Modelled SCDs are calculated by integrating the modelled gas concentration along the observational lines-of-sight given as a function of height and solar zenith angle (e.g. Butz et al., 2007; Dorf et al., 2008). Modelled SCDs for different loadings of $\mathrm{I}_{\mathrm{y}}$ are readily computed by scaling the model run for $0.2 \mathrm{ppt} \mathrm{I}_{\mathrm{y}}$.

Figure 5 compares the modelled SCDs to the measured upper limits of IO and OIO derived in Sect. 3. Modelled $\mathrm{SCDs}$ are shown for different $\mathrm{I}_{\mathrm{y}}$ amounts (integer multiples of $0.1 \mathrm{ppt}$ ). The intersections of the measured upper limits with the underlying grid of modelled SCDs yield upper limits of $\mathrm{I}_{\mathrm{y}}$ compatible with our measurements under the assumption that the $\mathrm{I}_{\mathrm{y}}$ volume mixing ratio is constant along individual lines-of-sight. Such $\mathrm{I}_{\mathrm{y}}$ upper limits for all measurements are shown in Fig. 6. Sunset observations from the balloon flight in June, 2008, provide an illustrative example for the employed approach (Fig. 5, left panel, subpanel c). Between $\sim 21 \mathrm{~km}$ and $\sim 17 \mathrm{~km}$ tangent height the IO SCD upper limits closely follow the modelled IO SCDs for $0.1 \mathrm{ppt}$ $\mathrm{I}_{\mathrm{y}}$ in the atmosphere (lowest black line). Thus, the estimate of the corresponding $\mathrm{I}_{\mathrm{y}}$ upper limit is $0.1 \mathrm{ppt}$. The photochemical modelling error is taken into account by attributing it to the measured IO and OIO upper limits (blue dotted lines in Fig. 5).

For our observations, IO measurements generally put tighter constraints on the compatible $\mathrm{I}_{\mathrm{y}}$ burden than OIO except for the flight from June 2005 for upper tropospheric tangent heights. In the latter case, $\mathrm{I}_{\mathrm{y}}$ upper limits derived from OIO are slightly lower than those inferred from IO. However, this is only true if OIO photolysis is omitted in the model runs. If OIO photolysis is efficient, IO provides the by far better constraint on $\mathrm{I}_{\mathrm{y}}$ in all cases. Lowest $\mathrm{I}_{\mathrm{y}}$ upper limits are deduced from IO measurements in 2008 where instrument performance and flight planning was optimized for our purposes. In the upper troposphere $(16.5 \mathrm{~km}$ to $13.5 \mathrm{~km})$ the best $\mathrm{I}_{\mathrm{y}}$ upper limit is 0.17 to $0.35(+0.20 /-0.08)$ ppt. Sampling sensitivity peaks in the lower stratosphere $(21 \mathrm{~km}$ to $16.5 \mathrm{~km})$ constraining $\mathrm{I}_{\mathrm{y}}$ to at most 0.09 to $0.16(+0.10 /-0.04)$ ppt. In the middle stratosphere ( $30 \mathrm{~km}$ to $21 \mathrm{~km})$, best estimates for $\mathrm{I}_{\mathrm{y}}$ upper limits are 0.36 to $0.18(+0.10 /-0.08)$ ppt increasing for higher altitudes due to decreasing sampling sensitivity. Given uncertainties refer to the photochemical modelling error. 


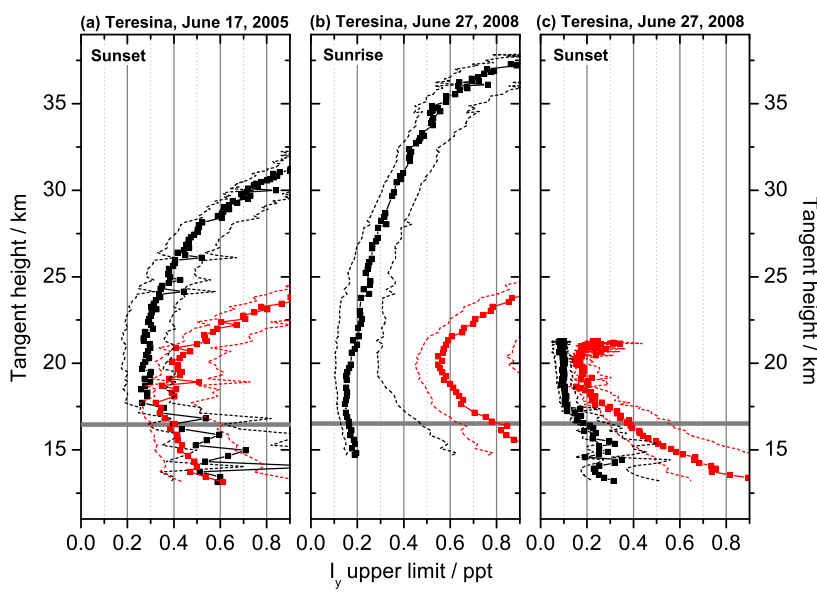

Fig. 6. $\mathrm{I}_{\mathrm{y}}$ upper limits derived from IO (black boxes) and OIO (red boxes) SCDs as a function of tangent height for sunset on 17 June 2005 (a), for sunrise on 27 June 2008 (b), and for sunset on 27 June 2008 (c). Dotted lines indicate photochemical modelling uncertainties. The horizontal grey line tentatively marks the tropopause.

\section{Discussion}

Neither IO nor OIO can be detected unambiguously by our observational approach in the tropical upper troposphere and stratosphere. We find upper limits for the concentrations of both gases which put the strongest constraints on their abundance at the region in the Earth's atmosphere where tropospheric air enters the stratosphere to date. Our findings are consistent with previous studies that conclude undetectably low amounts of IO and OIO in the high- and mid-latitude stratosphere (e.g Wennberg et al., 1997; Pundt et al., 1998; Bösch et al., 2003; Berthet et al., 2003). We point out that the inferred upper limits for IO depend on the absorption cross section used for the spectral retrieval. Recently Gómez Martín et al. (2005), Spietz et al. (2005), and Dillon et al. (2005) showed that the absorption cross section used here might be too small implying that our IO upper limits would be lower by a factor $\sim 0.75$ when using the absorption cross section of Spietz et al. (2005) convolved to our spectral resolution. Upper limits of total gaseous inorganic iodine $\mathrm{I}_{\mathrm{y}}$ (deduced from IO) would be lower by the same factor. This rationale also applies to our precursor study by Bösch et al. (2003) who used the same IO absorption cross section as employed here.

Our findings for IO are somewhat ambiguous since the spectral retrieval suggests a non-zero IO absorption signal in the UT/LS for two out of three solar occultation events. For reasons outlined above, we do not consider this signal as definitely true absorption but as an upper limit for the abundance of IO. However, we cannot totally exclude that the signal detected by the spectral retrieval comes from non-zero
IO abundances in the tropical UT/LS, which then could be as high as our upper limits. It might be interesting to note that the IO signal only exceeds the statistical detection limit for the two solar occultation events during sunset. The spectra recorded during the considered sunrise event do not show any sign of IO in the UT/LS although the spectral retrieval faces the same problems as for the sunset spectra. Thus, it is tempting to speculate that IO is actually detected for some of the sunset spectra and that the diurnal variation of the $\mathrm{I}_{\mathrm{y}}$ partitioning due to unknown photochemistry does not allow for detection during the sunrise event. Since we cannot finally decide on this issue, our approach to treat upper limits of IO conservatively covers all discussed possibilities.

Our balloon-borne payload intrinsically provides only snapshot-like observations. One might argue that the inferred upper limits for the upper tropospheric and stratospheric iodine content are not generally valid for tropical latitudes. Moreover, the introduction emphasizes that transport of iodine-bearing compounds into the tropical UT/LS potentially is most efficient for convective events which can uplift boundary layer air masses on the hourly timescale. Hence, we might simply have missed probing iodine-rich air masses. Fast convective motion is assumed to dominate air mass transport into the lower part of the tropical tropopause layer (TTL) ( $\sim 14 \mathrm{~km}$ to $\sim 18 \mathrm{~km})$, but convective events only rarely penetrate the lower stratosphere (Fueglistaler et al., 2009). Upward transport of air masses from the TTL into the tropical stratosphere is controlled by the large-scale dynamics of the Brewer-Dobson circulation implying comparatively slow ascent that leaves time for horizontal mixing and for processing of organic source gases to inorganic product gases. Ascent velocities in the tropical lower stratosphere are estimated to a few tenths of a $\mathrm{mm} / \mathrm{s}$ implying that the mean time since air masses around $20 \mathrm{~km}(\sim 475 \mathrm{~K})$ entered the stratosphere is several months (Andrews et al., 2001; Schoeberl et al., 2008). We concede that our observations in the tropical tropopause layer might be affected by local variability of air masses. However, local effects become less important the further up air masses ascend into the stratosphere. Thus, we consider our observations in the tropical lower stratosphere, in particular a few kilometers above the tropopause where our sampling sensitivity peaks, representative for the lower stratospheric environment on a larger spatial scale. Our findings complement the evidence accumulated previously for high and mid-latitudes that gaseous inorganic iodine abundances in the lower stratosphere are low on a global scale.

The employed method allows for investigation of the inorganic gaseous iodine budget by combining observations of IO and OIO with a photochemical model of the gaseous iodine partitioning. However, our method cannot assess if and how much iodine exists in physical or chemical forms other than accessible directly through our measurements or indirectly through the adopted photochemical scheme. The latter entails considerable uncertainties which are accounted for 
by the photochemical modelling error to the best of the current knowledge. This error can amount to a factor of 2 in our estimates of $\mathrm{I}_{\mathrm{y}}$. A major error contribution, for example, comes from the findings of Joseph et al. (2007) suggesting that $\mathrm{IONO}_{2}$ photolysis could be an order of magnitude slower than previously assumed. Further, the question remains to be answered if OIO photolysis occurs and what the product channels are. Higher iodine oxides such as $\mathrm{I}_{2} \mathrm{O}_{3}$, $\mathrm{I}_{2} \mathrm{O}_{4}, \mathrm{I}_{2} \mathrm{O}_{5}$, which might form in the marine boundary layer (e.g. Kaltsoyannis and Plane, 2008), are not considered by our photochemical scheme. We assume that $\mathrm{I}_{\mathrm{y}}$ concentrations of a few tenths of a ppt discussed here, are too low to produce these species.

There is evidence that iodine can be found in lower stratospheric aerosol (e.g. Fig. 3 in Murphy et al., 2007) which might be upward transported from the lower troposphere. It is subject of current debate how iodine forms aerosols through polymerization and to what extent inorganic or organic iodine compounds can be taken up by aerosols (e.g. Pechtl et al., 2006, 2007; Gilfedder et al., 2008). If considerable amounts of iodine are bound by aerosols or ice particles in the upper tropical troposphere and lower stratosphere, release of iodine species to the gas-phase would probably occur through evaporation in the middle to upper stratosphere where our measurements are less sensitive. On the other hand, a light-dependent pathway of $\mathrm{CH}_{3} \mathrm{I}$ production from the open ocean has been suggested (e.g. Richter and Wallace, 2004). If applicable to $\mathrm{CH}_{3} \mathrm{I}$ bound by aerosols, such a mechanism could potentially release gaseous iodine from aerosols into the UT/LS.

Implications for stratospheric ozone have been discussed in detail by Bösch et al. (2003), WMO-2006, and Li et al. (2006). As briefly outlined by the introduction, reactive iodine can undergo several catalytic ozone loss cycles either self-catalytically (Reactions R1 and R13) or through coupling with reactive hydrogen (Reaction R5), reactive nitrogen (Reaction R4), reactive chlorine (Reaction R9) or bromine (Reaction R11). Based on a photochemical scheme that involves these cycles, Li et al. (2006) found that the ozone depletion efficiency of inorganic iodine in the tropical lower stratosphere is up to 500 times greater than the one for inorganic chlorine owing to the large fraction of $\mathrm{I}_{\mathrm{y}}$ being reactive iodine (see also Fig. 4). The relative importance of the iodine-involving ozone loss cycles strongly depends on the availability of the respective reaction partners. Li et al. (2006) inferred that in the mid-latitude UT/LS all cycles contribute with $\mathrm{IO}+\mathrm{HO}_{2}$ being most important in the upper troposphere and the interhalogen and selfcatalytic cycles being dominant in the lower stratosphere. WMO-2006 point out that uncertainties in the reaction kinetics might jeopardize findings on the importance of iodine for the lower stratospheric ozone budget. Particular importance is attributed to reaction of $\mathrm{IO}$ with $\mathrm{BrO}$ (Reaction R10), reaction of IO with $\mathrm{HO}_{2}$ (Reaction R5), and photolysis of OIO. Concerning the latter, the product channel IO+O (Reaction R16) constitutes a null cycle for ozone loss and the product channel $\mathrm{I}+\mathrm{O}_{2}$ (Reaction R17) yields catalytic ozone destruction. A model, that uses different recommendations for the kinetics of these reactions, shows that the fractional contribution of $0.1 \mathrm{ppt}$ iodine to ozone loss in the lowermost mid-latitude stratosphere can range between $1 \%$ and $10 \%$ depending on the adopted kinetics. From a 2-dimensional latitude-height model based on the chemical reactions outlined in Sect. 4, Bösch et al. (2003) inferred that $0.1 \mathrm{ppt} \mathrm{I}_{\mathrm{y}}$ cause at most $0.8 \%$ decrease of the zonal mean $\mathrm{O}_{3}$ in the lower tropical stratosphere. For the high- and mid-latitude lower stratosphere, zonal mean $\mathrm{O}_{3}$ was decreased by at most $\sim 1 \%$. The impact of iodine on ozone in the upper and mid-stratosphere was found less important. The photochemical scheme adopted here and in Bösch et al. (2003), tends to maximize the impact of iodine on ozone. Overall, the inferred upper limits for total gaseous inorganic iodine in the tropical UT/LS allow for a minor contribution of iodine to catalytic loss of ozone. It is unclear to what extent reactive iodine has contributed to the observed declining trend of lower stratospheric ozone which is estimated roughly $-3 \%$ between 1979 and 2004 (WMO-2006). Thereby, reactive iodine could amplify the effect of reactive chlorine and bromine through coupled catalytic cycles. In a future climate, emission of iodine-bearing source gases and transport efficiency into the upper atmosphere might increase or other iodine-containing gases such as $\mathrm{CF}_{3} \mathrm{I}$ (considered for replacement of halons in aircraft) might be directly injected into the upper atmosphere ( $\mathrm{Li}$ et al. (2006), WMO-2006). Thus, monitoring of reactive iodine abundances in the lower stratosphere seems warranted.

\section{Conclusions}

Our study reports on the to date lowest upper limits of IO and OIO in the tropical upper troposphere and stratosphere. Neither IO nor OIO absorption can be unambiguously detected in solar occultation spectra recorded during two stratospheric balloon flights conducted in tropical Brazil. Upper limits for IO are $0.04 \mathrm{ppt}, 0.08 \mathrm{ppt}$, and $0.07 \mathrm{ppt}$ at $20 \mathrm{~km}, 16.5 \mathrm{~km}$, and $13.5 \mathrm{~km}$, and for OIO $0.06 \mathrm{ppt}, 0.05 \mathrm{ppt}$, and $0.05 \mathrm{ppt}$ at $20 \mathrm{~km}, 16.5 \mathrm{~km}$, and $13.5 \mathrm{~km}$, respectively. A photochemical model of the partitioning among inorganic iodine species yields corresponding upper limits for the total gaseous inorganic iodine burden of 0.17 to $0.35(+0.20 /-0.08) \mathrm{ppt}$ in the tropical upper troposphere $(16.5 \mathrm{~km}$ to $13.5 \mathrm{~km})$ and 0.09 to $0.16(+0.10 /-0.04) \mathrm{ppt}$ in the tropical lower stratosphere $(21.0 \mathrm{~km}$ to $16.5 \mathrm{~km})$ where the errors refer to uncertainties of the photochemical model. Upper limits increase in the middle stratosphere due to decreasing sampling sensitivity. However, photochemical modelling of iodine photochemistry is hindered by sizable uncertainties of the involved reaction kinetics such as the photolysis rates of $\mathrm{IONO}_{2}$ and OIO. Our study cannot assess how much iodine enters the stratosphere in particulate form. 
Given the current understanding of iodine photochemistry, our study suggests that the amount of gaseous iodine-bearing compounds transported into the tropical lower stratosphere is low. The inferred upper limits allow for a minor contribution of iodine-involving catalytic cycles to total ozone loss, but it remains unclear whether reactive iodine contributes possibly through coupling with chlorine or bromine - to the observed trend of declining ozone in the lower stratosphere. In the future, the importance of iodine-mediated ozone loss could grow if source gas emissions or transport efficiency to the upper atmosphere increase or if iodine-bearing gases such as $\mathrm{CF}_{3} \mathrm{I}$ are directly injected into the lower stratosphere.

Acknowledgements. Funding for this study came from Deutsches Zentrum für Luft und Raumfahrt (DLR) (contracts BMBF 50EE0017 and VH-VI-156), the European Union (EU) through the SCOUT-O3 project (contract 505390-GOCE-CT-2004) and the European Space Agency (ESA) (contract 20752/07/I-OL). We thank CNES (Centre National d'Études Spatiales, France) and INPE (Instituto Nacional De Pesquisas Espaciais, Brazil) for providing ballooning operations and for setting up the necessary infrastructure. We are grateful to Karla Longo and Saulo R. Freitas (INPE) for assistance given to balloon launches at Timon, Brazil. Helpful comments by Arno de Lange are greatly appreciated.

Edited by: A. Hofzumahaus

\section{References}

Aliwell, S. R., Van Roozendael, M., Johnston, P. V., Richter, A., Wagner, T., Arlander, D. W., Burrows, J. P., Fish, D. J., Jones, R. L., Tørnkvist, K. K., Lambert, J.-C., Pfeilsticker, K., and Pundt, I.: Analysis for BrO in zenith-sky spectra: An intercomparison exercise for analysis improvement, J. Geophys. Res., 107, 4199, doi:10.1029/2001JD000329, 2002.

Andrews, A. E., Boering, K. A., Daube, B. C., Wofsy, S. C., Loewenstein, M., Jost, H., Podolske, J. R., Webster, C. R., Herman, R. L., Scott, D. C., Flesch, G. J., Moyer, E. J., Elkins, J. W., Dutton, G. S., Hurst, D. F., Moore, F. L., Ray, E. A., Romashkin, P. A., and Strahan, S. E.: Mean ages of stratospheric air derived from in situ observations of $\mathrm{CO}_{2}, \mathrm{CH}_{4}$, and $\mathrm{N}_{2} \mathrm{O}$, J. Geophys. Res., 106, 32295-32314, doi:10.1029/2001JD000465, 2001.

Berthet, G., Renard, J.-B., Chartier, M., Pirre, M., and Robert, C.: Analysis of $\mathrm{OBrO}, \mathrm{IO}$, and $\mathrm{OIO}$ absorption signature in UV-visible spectra measured at night and at sunrise by stratospheric balloon-borne instruments, J. Geophys. Res., 108, 4161, doi:10.1029/2002JD002284, 2003.

Bloss, W. J., Rowley, D. M., Cox, R. A., and Jones, R. L.: Kinetics and Products of the IO Self-Reaction, J. Phys. Chem. A, 105, 7840-7854, 2001.

Bösch, H., Camy-Peyret, C., Chipperfield, M. P., Fitzenberger, R., Harder, H., Platt, U., and Pfeilsticker, K.: Upper limits of stratospheric IO and OIO inferred from center-to-limb-darkeningcorrected balloon-borne solar occultation visible spectra: Implications for total gaseous iodine and stratospheric ozone, J. Geophys. Res., 108, 4455, doi:10.1029/2002JD003078, 2003.
Brault, J. and Neckel, H.: Solar spectra. Provided by Hamburger Sternwarte, distributed through http://www.hs.uni-hamburg.de/ DE/Oef/Inf/Einbl/Sospec/sonnspec.html, 1987.

Butler, J. H., King, D. B., Lobert, J. M., Montzka, S. A., YvonLewis, S. A., Hall, B. D., Warwick, N. J., Mondeel, D. J., Aydin, M., and Elkins, J. W.: Oceanic distributions and emissions of short-lived halocarbons, Global Biogeochem. Cy., 21, B1023, doi:10.1029/2006GB002732, 2007.

Butz, A., Bösch, H., Camy-Peyret, C., Dorf, M., Engel, A., Payan, S., and Pfeilsticker, K.: Observational constraints on the kinetics of the $\mathrm{ClO}-\mathrm{BrO}$ and $\mathrm{ClO}-\mathrm{ClO}$ ozone loss cycles in the Arctic winter stratosphere, Geophys. Res. Lett., 34, 5801, doi:10.1029/ 2006GL028718, 2007.

Camy-Peyret, C., Jeseck, P., Hawat, T., Durry, G., Payan, S., Berube, G., Rochette, L., and Huguenin, D.: The LPMA Balloon-Borne FTIR Spectrometer: Remote Sensing of Atmospheric Constituents, Proceedings of the 12th ESA Symposium on Rocket and Balloon Programmes and Related Research, Lillehammer, Norway, 323-328, 1995.

Chipperfield, M. P.: Multiannual simulations with a threedimensional chemical transport model, J. Geophys. Res., 104, 1781-1805, 1999.

Chipperfield, M. P.: New version of the TOMCAT/SLIMCAT offline chemical transport model: Intercomparison of stratospheric tracer experiments, Q. J. Roy. Meteorol. Soc., 132, 1179-1203, doi:10.1256/qj.05.51, 2006.

Cox, R. A., Bloss, W. J., Jones, R. L., and Rowley, D. M.: OIO and the atmospheric cycle of iodine, Geophys. Res. Lett., 26, 18571860, doi:10.1029/1999GL900439, 1999.

Davis, D., Crawford, J., Liu, S., McKeen, S., Bandy, A., Thornton, D., Rowland, F., and Blake, D.: Potential impact of iodine on tropospheric levels of ozone and other critical oxidants, J. Geophys. Res., 101, 2135-2147, doi:10.1029/95JD02727, 1996.

Dillon, T. J., Tucceri, M. E., Hölscher, D., and Crowley, J. N.: Absorption cross-section of IO at $427.2 \mathrm{~nm}$ and $298 \mathrm{~K}$, J. Photochem. Photobio. A: Chemistry, 176, 3-14, 2005.

Dorf, M.: Investigation of Inorganic Stratospheric Bromine using Balloon-Borne DOAS Measurements and Model Simulation, online available at: http://www.ub.uni-heidelberg.de/archiv/6093, Phd thesis, University of Heidelberg, 2005.

Dorf, M., Butler, J. H., Butz, A., Camy-Peyret, C., Chipperfield, M. P., Kritten, L., Montzka, S. A., Simmes, B., Weidner, F., and Pfeilsticker, K.: Long-term observations of stratospheric bromine reveal slow down in growth, Geophys. Res. Lett., 33, 24803, doi:10.1029/2006GL027714, 2006.

Dorf, M., Butz, A., Camy-Peyret, C., Chipperfield, M. P., Kritten, L., and Pfeilsticker, K.: Bromine in the tropical troposphere and stratosphere as derived from balloon-borne BrO observations, Atmos. Chem. Phys., 8, 7265-7271, 2008, http://www.atmos-chem-phys.net/8/7265/2008/.

Ferlemann, F., Bauer, N., Fitzenberger, R., Harder, H., Osterkamp, H., Perner, D., Platt, U., Schneider, M., Vradelis, P., and Pfeilsticker, K.: Differential Optical Absorption Spectroscopy Instrument for Stratospheric Balloonborne Trace-Gas Studies, Appl. Opt., 39, 2377-2386, doi:10.1364/AO.39.002377, 2000.

Finley, B. D. and Saltzman, E. S.: Observations of $\mathrm{Cl}_{2}, \mathrm{Br}_{2}$, and $\mathrm{I}_{2}$ in coastal marine air, J. Geophys. Res., 113, 21301, doi:10.1029/ 2008JD010269, 2008.

Frieß, U., Wagner, T., Pundt, I., Pfeilsticker, K., and Platt, U.: Spec- 
troscopic measurements of tropospheric iodine oxide at Neumayer station, Antarctica, Geophys. Res. Lett., 28, 1941-1944, doi:10.1029/2000GL012784, 2001.

Fueglistaler, S., Dessler, A. E., Dunkerton, T. J., Folkins, I., Fu, Q., and Mote, P. W.: Tropical tropopause layer, Rev. Geophys., 47, 1004, doi:10.1029/2008RG000267, 2009.

Gilfedder, B. S., Lai, S. C., Petri, M., Biester, H., and Hoffmann, T.: Iodine speciation in rain, snow and aerosols, Atmos. Chem. Phys., 8, 6069-6084, 2008,

http://www.atmos-chem-phys.net/8/6069/2008/.

Gómez Martín, J. C., Spietz, P., and Burrows, J. P.: Spectroscopic studies of the $\mathrm{I}_{2} / \mathrm{O}_{3}$ photochemistry Part 1: Determination of the absolute absorption cross sections of iodine oxides of atmospheric relevance, J. Photochem. Photobio. A: Chemistry, 176, 15-38, 2005.

Gómez Martín, J. C., Spietz, P., and Burrows, J. P.: Kinetic and Mechanistic Studies of the $\mathrm{I}_{2} / \mathrm{O}_{3}$ Photochemistry, J. Phys. Chem. A, 111, 306-320, 2007.

Gómez Martín, J. C., Ashworth, S. H., Mahajan, A. S., and Plane, J. M. C.: Photochemistry of OIO: Laboratory study and atmospheric implications, Geophys. Res. Lett., 36, L09802, doi:10.1029/2009GL037642, 2009.

Harder, J. W., Brault, J. W., Johnston, P. V., and Mount, G. H.: Temperature dependent $\mathrm{NO}_{2}$ cross sections at high spectral resolution, J. Geophys. Res., 102, 3861-3880, doi:10.1029/ 96JD03086, 1997.

Hermans, C., Vandaele, A. C., Carleer, M., Fally, S., Colin, R., Jenouvrier, A., Coquart, B., and Mérienne, M.-F.: Absorption Cross-Sections of Atmospheric Constituents: $\mathrm{NO}_{2}, \mathrm{O}_{2}$, and $\mathrm{H}_{2} \mathrm{O}$, Environ. Sci. \& Pollut. Res., 6, 151-158, 1999.

Hönninger, G.: Referenzspektren reaktiver Halogenverbindungen für DOAS-Messungen, Diploma thesis, University of Heidelberg, 1999.

Ingham, T., Cameron, M., and Crowley, J. N.: Photodissociation of IO $(355 \mathrm{~nm})$ and OIO $(532 \mathrm{~nm})$ : Quantum Yields for $\mathrm{O}\left({ }^{3} \mathrm{P}\right)$ and $\mathrm{I}\left({ }^{2} \mathrm{P}_{J}\right)$ Production, J. Phys. Chem. A., 104, 8001-8010, 2000.

Jensen, E. J., Pfister, L., Bui, T. V., Lawson, P., Baker, B., Mo, Q., Baumgardner, D., Weinstock, E. M., Smith, J. B., Moyer, E. J., Hanisco, T. F., Sayres, D. S., Clair, J. M. S., Alexander, M. J., Toon, O. B., and Smith, J. A.: Formation of large $(\simeq 100 \mu \mathrm{m})$ ice crystals near the tropical tropopause, Atmos. Chem. Phys., 8, 1621-1633, 2008,

http://www.atmos-chem-phys.net/8/1621/2008/.

Joseph, D. M., Ashworth, S. H., and Plane, J. M. C.: The absorption cross-section and photochemistry of OIO, J. Photochem. Photobio. A: Chemistry, 176, 68-77, 2005.

Joseph, D. M., Ashworth, S. H., and Plane, J. M. C.: On the photochemistry of $\mathrm{IONO}_{2}$ : absorption cross section (240-370 nm) and photolysis product yields at $248 \mathrm{~nm}$, Phys. Chem. Chem. Phys., 9, 5599, doi:10.1039/b709465e, 2007.

Kaltsoyannis, N. and Plane, J. M. C.: Quantum chemical calculations on a selection of iodine-containing species (IO, OIO, INO3, (IO)2, I2O3, I2O4 and I2O5) of importance in the atmosphere, Phys. Chem. Chem. Phys., 10, 1723, doi:10.1039/b715687c, 2008.

Law, K. S., Sturges, W. T., Blake, D. R., Blake, N. J., Burkholder, J. B., Butler, J. H., Cox, R. A., Haynes, P. H., Ko, M. K. W., Kreher, K., Mari, C., Pfeilsticker, K., Plane, J. M. C., Salawitch, R. J., Schiller, C., Sinnhuber, B. M., von Glasow, R., Warwick,
N. J., Wuebbles, D. J., and Yvon-Lewis, S. A.: Halogenated very short-lived substances, Chapter 2 in Scientific Assessment of Ozone Depletion, Global Ozone and Research and Monitoring Project - Report No. 50, World Meteorological Organization, Geneva, Switzerland, 2006.

Lawson, R. P., Pilson, B., Baker, B., Mo, Q., Jensen, E., Pfister, L., and Bui, P.: Aircraft measurements of microphysical properties of subvisible cirrus in the tropical tropopause layer, Atmos. Chem. Phys., 8, 1609-1620, 2008, http://www.atmos-chem-phys.net/8/1609/2008/.

Li, Y., Patten, K. O., Youn, D., and Wuebbles, D. J.: Potential impacts of $\mathrm{CF}_{3} \mathrm{I}$ on ozone as a replacement for $\mathrm{CF}_{3} \mathrm{Br}$ in aircraft applications, Atmos. Chem. Phys., 6, 4559-4568, 2006, http://www.atmos-chem-phys.net/6/4559/2006/.

Mössinger, J. C., Rowley, D. M., and Cox, R. A.: The UV-visible absorption cross-sections of $\mathrm{IONO}_{2}$, Atmos. Chem. Phys., 2, 227-234, 2002, http://www.atmos-chem-phys.net/2/227/2002/.

Murphy, D. M. and Thomson, D. S.: Halogen ions and $\mathrm{NO}^{+}$in the mass spectra of aerosols in the upper troposphere and lower stratosphere, Geophys. Res. Lett., 27, 3217-3220, doi:10.1029/ 1999GL011267, 2000.

Murphy, D. M., Thomson, D. S., and Mahoney, M. J.: In Situ Measurements of Organics, Meteoritic Material, Mercury, and Other Elements in Aerosols at 5 to 19 Kilometers, Science, 282, 1664, doi:10.1126/science.282.5394.1664, 1998.

Murphy, D. M., Cziczo, D. J., Hudson, P. K., and Thomson, D. S.: Carbonaceous material in aerosol particles in the lower stratosphere and tropopause region, J. Geophys. Res., 112, 4203, doi: 10.1029/2006JD007297, 2007.

Park, S., Jiménez, R., Daube, B. C., Pfister, L., Conway, T. J., Gottlieb, E. W., Chow, V. Y., Curran, D. J., Matross, D. M., Bright, A., Atlas, E. L., Bui, T. P., Gao, R.-S., Twohy, C. H., and Wofsy, S. C.: The $\mathrm{CO}_{2}$ tracer clock for the Tropical Tropopause Layer, Atmos. Chem. Phys., 7, 3989-4000, 2007, http://www.atmos-chem-phys.net/7/3989/2007/.

Pechtl, S., Lovejoy, E. R., Burkholder, J. B., and von Glasow, R.: Modeling the possible role of iodine oxides in atmospheric new particle formation, Atmos. Chem. Phys., 6, 505-523, 2006, http://www.atmos-chem-phys.net/6/505/2006/.

Pechtl, S., Schmitz, G., and von Glasow, R.: Modelling iodide iodate speciation in atmospheric aerosol: Contributions of inorganic and organic iodine chemistry, Atmos. Chem. Phys., 7, 1381-1393, 2007, http://www.atmos-chem-phys.net/7/1381/2007/.

Peters, C., Pechtl, S., Stutz, J., Hebestreit, K., Hönninger, G., Heumann, K. G., Schwarz, A., Winterlik, J., and Platt, U.: Reactive and organic halogen species in three different European coastal environments, Atmos. Chem. Phys., 5, 3357-3375, 2005, http://www.atmos-chem-phys.net/5/3357/2005/.

Platt, U. and Stutz, J.: Differential Optical Absorption Spectroscopy (DOAS), Principle and Applications, ISBN: 3-34021193-4, Springer Verlag, Heidelberg, Germany, 2006.

Pundt, I., Pommereau, J. P., Phillips, C., and Lateltin, E.: Upper limits of iodine oxide in the lower stratosphere, J. Atmos. Chem., 30, 173-185, 1998.

Read, K. A., Mahajan, A. S., Carpenter, L. J., Evans, M. J., Faria, B. V. E., Heard, D. E., Hopkins, J. R., Lee, J. D., Moller, S. J., Lewis, A. C., Mendes, L., McQuaid, J. B., Oetjen, H., SaizLopez, A., Pilling, M. J., and Plane, J. M. C.: Extensive halogen- 
mediated ozone destruction over the tropical Atlantic Ocean, Nature, 453, 1232-1235, doi:10.1038/nature07035, 2008.

Richter, U. and Wallace, D. W. R.: Production of methyl iodide in the tropical Atlantic Ocean, Geophys. Res. Lett., 31(23), L23S03, doi:10.1029/2004GL020779, 2004.

Rothman, L. S., Jacquemart, D., Barbe, A., Chris Benner, D., Birk, M., Brown, L. R., Carleer, M. R., Chackerian, C., Chance, K., Dana, V., Devi, V. M., Flaud, J.-M., Gamache, R. R., Goldman, A., Hartmann, J.-M., Jucks, K. W., Maki, A. G., Mandin, J.Y., Massie, S. T., Orphal, J., Perrin, A., Rinsland, C. P., Smith, M. A. H., Tennyson, J., Tolchenov, R. N., Toth, R. A., Vander Auwera, J., Varanasi, P., and Wagner, G.: The HITRAN 2004 Molecular Spectroscopic Database, J. Quant. Spectrom. Rad. T., 96, 139-204, 2005.

Saiz-Lopez, A., Shillito, J. A., Coe, H., and Plane, J. M. C.: Measurements and modelling of $\mathrm{I}_{2}, \mathrm{IO}, \mathrm{OIO}, \mathrm{BrO}$ and $\mathrm{NO}_{3}$ in the mid-latitude marine boundary layer, Atmos. Chem. Phys., 6, 1513-1528, 2006, http://www.atmos-chem-phys.net/6/1513/2006/.

Saiz-Lopez, A., Chance, K., Liu, X., Kurosu, T. P., and Sander, S. P.: First observations of iodine oxide from space, Geophys. Res. Lett., 34, 12812, doi:10.1029/2007GL030111, 2007a.

Saiz-Lopez, A., Mahajan, A. S., Salmon, R. A., Bauguitte, S. J.B., Jones, A. E., Roscoe, H. K., and Plane, J. M. C.: Boundary Layer Halogens in Coastal Antarctica, Science, 317(348), 348351, doi:10.1126/science.1141408, 2007b.

Sander, S. P., Friedl, R. R., Ravishankara, A. R., Golden, D. M., Kolb, C. E., Kurylo, M. J., Molina, M. J., Moortgat, G. K., Keller-Rudek, H., Finlayson-Pitts, B. J., Pine, P. H., Huie, R. E., and Orkin, V. L.: Chemical Kinetics and Photochemical Data for Use in Atmospheric Studies, NASA/JPL-Publication, 2006.

Schoeberl, M. R., Douglass, A. R., Stolarski, R. S., Pawson, S., Strahan, S. E., and Read, W.: Comparison of lower stratospheric tropical mean vertical velocities, J. Geophys. Res., 113, 24109, doi:10.1029/2008JD010221, 2008.

Schönhardt, A., Richter, A., Wittrock, F., Kirk, H., Oetjen, H., Roscoe, H. K., and Burrows, J. P.: Observations of iodine monoxide columns from satellite, Atmos. Chem. Phys., 8, 637653, 2008, http://www.atmos-chem-phys.net/8/637/2008/.
Solomon, S., Garcia, R. R., and Ravishankara, A. R.: On the role of iodine in ozone depletion, J. Geophys. Res., 99, 20491-20500, doi:10.1029/94JD02028, 1994.

Spietz, P., Gómez Martín, J. C., and Burrows, J. P.: Spectroscopic studies of the $\mathrm{I}_{2} / \mathrm{O}_{3}$ photochemistry Part 2: Improved spectra of iodine oxides and analysis of the IO absorption spectrum, J. Photochem. Photobio. A: Chemistry, 176, 50-67, 2005.

Stutz, J. and Platt, U.: Numerical analysis and estimation of the statistical error of differential optical absorption spectroscopy measurements with least-squares methods, Appl. Opt., 35, 60416053, 1996.

Tucceri, M. E., Hölscher, D., Rodriguez, A., Dillon, T. J., and Crowley, J. N.: Absorption cross section and photolysis of OIO, Phys. Chem. Chem. Phys., 8, 834-846, 2006.

Wennberg, P. O., Brault, J. W., Hanisco, T. F., Salawitch, R. J., and Mount, G. H.: The atmospheric column abundance of IO: Implications for stratospheric ozone, J. Geophys. Res., 102, 88878898, doi:10.1029/96JD03712, 1997.

Wittrock, F., Müller, R., Richter, A., Bovensmann, H., and Burrows, J. P.: Measurements of Iodine monoxide (IO) above Spitsbergen, Geophys. Res. Lett., 27, 1471, doi:10.1029/ 1999GL011146, 2000.

Yano, J. I., Donner, L. J., Yin, Y., Lawrence, M. G., Mari, C., and Stohl, A.: Multidisciplinary Discussions of Convective Chemical Transport, EOS Transactions, 84, 327-330, doi:10.1029/ 2003EO340005, 2003.

Yokouchi, Y., Osada, K., Wada, M., Hasebe, F., Agama, M., Murakami, R., Mukai, H., Nojiri, Y., Inuzuka, Y., Toom-Sauntry, D., and Fraser, P.: Global distribution and seasonal concentration change of methyl iodide in the atmosphere, J. Geophys. Res., 113, 18311, doi:10.1029/2008JD009861, 2008.

Zingler, J. and Platt, U.: Iodine oxide in the Dead Sea Valley: Evidence for inorganic sources of boundary layer IO, J. Geophys. Res., 110, 7307, doi:10.1029/2004JD004993, 2005. 